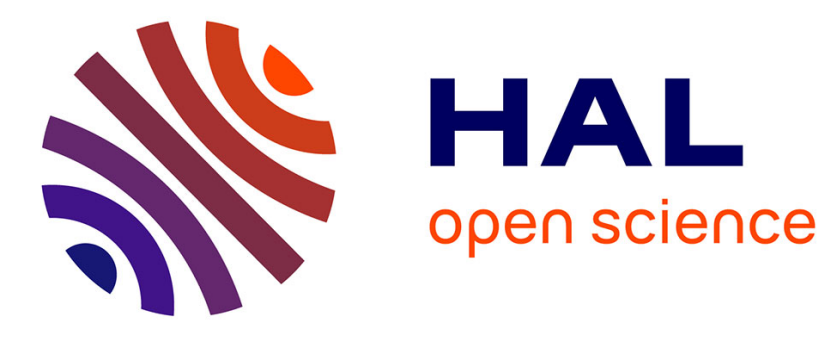

\title{
Helping farmers to reduce herbicide environmental impacts
}

\author{
F. Le Bellec, A. Velu, P. Fournier, Sandrine Le Squin, S. Michels, D. Tendero, \\ Christian C. Bockstaller
}

\section{- To cite this version:}

F. Le Bellec, A. Velu, P. Fournier, Sandrine Le Squin, S. Michels, et al.. Helping farmers to reduce herbicide environmental impacts. Ecological Indicators, 2015, 54, pp.207-216. 10.1016/j.ecolind.2015.02.020 . hal-02630233

\section{HAL Id: hal-02630233 https://hal.inrae.fr/hal-02630233}

Submitted on 27 May 2020

HAL is a multi-disciplinary open access archive for the deposit and dissemination of scientific research documents, whether they are published or not. The documents may come from teaching and research institutions in France or abroad, or from public or private research centers.
L'archive ouverte pluridisciplinaire HAL, est destinée au dépôt et à la diffusion de documents scientifiques de niveau recherche, publiés ou non, émanant des établissements d'enseignement et de recherche français ou étrangers, des laboratoires publics ou privés. 


\title{
Helping farmers to reduce herbicide environmental impacts
}

\author{
F. Le Bellec ${ }^{\mathrm{a}, *}$, A. Vélu $^{\mathrm{a}}$, P. Fournier ${ }^{\mathrm{b}}$, S. Le Squin ${ }^{\mathrm{c}}$, T. Michels $^{\mathrm{a}}$, A. Tendero ${ }^{\mathrm{d}}$, C. Bockstaller $^{\mathrm{e}}$ \\ a CIRAD, UPR HortSys, F-97455 Saint-Pierre, France \\ b CIRAD, UPR 26, F-97455 Saint-Pierre, France \\ c CIRAD, UMR PVBMT, F-97410 Saint-Pierre, France \\ d CIRAD, UPR AIDA, F-97410 Saint-Pierre, France \\ e INRA, UMR1121 INPL/ENSAIA/INRA, F-68021 Colmar, France
}

\section{A R T I C L E I N F O}

\section{Article history:}

Received 21 March 2014

Received in revised form 10 February 2015

Accepted 12 February 2015

\section{Keywords:}

Herbicides

Environmental indicator

Decision-support Tool

Field

Best management practice

Tropical climate

CART

\begin{abstract}
A B S T R A C T
While pesticides help to effectively control crop pests, their collateral effects often harm the environment. On the French island of Reunion in the Indian Ocean, over $75 \%$ of the pesticides used are herbicides and they are regularly detected in water. Agri-environmental models and pesticide risk indicators can be used to predict and to help pesticide users to reduce environmental impacts. However, while the complexity of models often limits their use to the field of research, pesticide risk indicators, which are easier to implement, do not explicitly identify the technical levers that farmers can act upon to limit such transfers on their scale of action (the field). The aim of this article is to contribute to developing a decision support tool to guide farmers in implementing relevant practices regarding the reduction of pesticide transfers. In this article, we propose a methodology based on classification and regression trees. We applied our methodology to a pesticide risk indicator (I-PHY indicator) for identifying the importance of the variables, their interactions and relative weight in contributing to the score of the indicator. We applied our methodology to the assessment of transfer risks linked to the use of 20 herbicides applied to all soils in Reunion and according to different climate, plot management and product application scenarios (4096 scenarios tested). We constructed regression trees which identified, for each herbicide on each soil type, the contribution made by each input variable to the construction of the indicator score. The tree is represented graphically, and this aids exploration and understanding. The 20 herbicides were divided into 3 groups that differed through the main contributing variable to the indicator score. These variables were all technical levers available to farmers to limit transfer risks. These trees then become decision support tools specific to each pesticide user, enabling them to take appropriate decisions with a view to reducing pesticide environmental impacts.
\end{abstract}

(c) 2015 Elsevier Ltd. All rights reserved.

\section{Introduction}

While pesticides help in effectively controlling the main crop pests (including weeds), their collateral effects are often harmful to human health (Pedlowski et al., 2012) and more generally to biodiversity (Pedlowski et al., 2012; Reichenberger et al., 2007). According to the FAO (Food and Agriculture Organization of the United Nations), based on statistics from 58 countries, almost $43 \%$ of the pesticide volumes applied worldwide in 2010 were herbicides (FAOSTAT, 2013). On the French island of Reunion in the western Indian Ocean (located at $21^{\circ} 06 \mathrm{~S}, 55^{\circ} 36 \mathrm{E}$ ), the predominance of herbicides is even more marked. In $2011,75 \%$ of the pesticide volumes sold were herbicides (Maillary, 2012). The

\footnotetext{
* Corresponding author. Tel.: +262 262969587.

E-mail address: lebellec@cirad.fr (F. Le Bellec).
}

sustainable development objectives of the island are spearheaded by the Parc National de la Réunion (70\% of the island's area belongs to the UNESCO World Heritage List) and encompass the reduction of surface water and groundwater contamination. Indeed, in 2010, out of 21 active ingredients found in the waters of Reunion, 17 were herbicides or their degradation products (Badat, 2011). Such contamination can be linked to poor agricultural practices (wrong choice of herbicide, equipment or application conditions, etc.) but also to local pedoclimatic and topographical conditions (Oliver and Kookana, 2006; Davis et al., 2011; Mottes et al., 2013), which can vary substantially in the Tropics. For example, in Reunion, rainfall varies from 600 to $7000 \mathrm{~mm}$ year $^{-1}$ and slopes from 0 to $45 \%$. In the circumstances, replacing one herbicide by another and/or appropriate application conditions would help to limit environmental impacts (Reichenberger et al., 2007). Decision-support tools are needed to help farmers identify relevant technical levers to deal with this issue of reducing water contamination by herbicides. 
The degree of herbicide transport in the environment depends on several factors, such as the application rate, herbicide persistence and mobility, rainfall, topography, and climate (Lin et al., 1999). Pesticides in soil are subject to sorption as well as several biological and chemical degradation mechanisms. These involve chemical, microbial, and photodecomposition, which lead to a decrease in pesticide concentrations in the soil. Pesticides may be transported to different parts of the environment by volatilization, runoff erosion, and leaching. Transport by runoff and leaching may cause the contamination of surface water and groundwater. Many models can be used to simulate these different pollution processes (Mottes et al., 2013) but their complexity often limits their use to the field of research and to specific assessment situations (Voltz et al., 2005). Many pesticide environmental risk indicators based on operational models that are easier to implement have been developed for predicting or assessing the environmental risks linked to pesticide use (Bockstaller et al., 2009; Payraudeau and Gregoire, 2012). These pesticide risk indicators can be used to assess these risks, which are often difficult to perceive as a whole (Payraudeau and Gregoire, 2012; Reus et al., 2002). However, as these indicators are less accurate than models, Voltz et al. (2005) recommended using them as a decision-support tool to prioritize risk situations rather than as a tool to predict pesticide flows.

These pesticide risk indicators combine a more or less large number of variables and consider agricultural practices and application conditions to varying degrees (Devilliers et al., 2005). All indicators produce a score to reflect environmental risk or performance; this outcome is generally the only result. Indeed, indicators do not explicitly provide information on the levers for action to be acted upon in order to improve practices. The large number of variables used and their interactions, but also the aggregation methods and the often incomplete sensitivity analyses of these indicators (Devillers et al., 2005), make the search for levers a complex business. This finding contributes to the "black box" image that such tools are often criticized for; this is also why these indicators are rarely decision-support tools for farmers (Reus et al., 2002).

In this article, we propose some solutions for analysing these levers which, to our knowledge, have yet to be explored. We applied our methodology, based on classification and regression trees, to the I-PHY indicator of the assessment method INDIGO (Bockstaller et al., 2009). We tested this indicator and our method to assess the environmental risks associated with the application of 20 herbicide active ingredients used in Reunion. We then discuss our results and our method to identify and prioritize importance variables for this indicator in order to make it a decision-support tool for farmers.

\section{Materials and methods}

\subsection{I-PHY indicator}

The pesticide risk indicator I-PHY was developed in parallel to other environmental indicators for the assessment method INDIGO (Bockstaller et al., 2009). The score of the indicator was published by Van der Werf and Zimmer (1998) and enhanced, adapted and tested for arable farming (Bockstaller et al., 2008). Since then, I-PHY has been adapted to other farming systems such as wine growing, fruit production, field vegetable production, palm trees, etc. In the last 5 years, the I-PHY indicator has been used in more than 100 cases in France by advisers mainly working on the assessment of risks at field/farm level or working on the development of innovative cropping systems (Bockstaller et al., 2008).

Calculation of the indicator is based on four components respectively assessing the risk linked to the amount of active ingredient (a.i.) applied and the risk for groundwater, surface water and air.
In a second step, an overall indicator is calculated. Three types of input variables are used (Table 1 ):

1. Pesticide properties related to environmental fate or to the ecotoxicology effect,

2. Site-specific conditions (e.g. runoff sensitivity),

3. Characteristics of pesticide application (e.g. rate of application).

A fuzzy expert system is used to aggregate all these heterogeneous variables into indicator modules and to subsequently aggregate these modules into a synthetic indicator. By using fuzzy subsets the effect of a knife-edge limit of a given class can be avoided. Output values for each module, as well as for the overall indicator, are expressed on a qualitative scale used in the INDIGO method: between 0 (maximum risk) and 10 (no risk) with a reference value of 7 (maximum acceptable risk).

Fig. 1 shows an example for groundwater risk where the main weight is given to a pesticide property variable (ground water ubiquity score - GUS) (Gustafson, 1989), with less weight given to position (crop interception here) and soil sensitivity to leaching. Aggregation rules are defined according to knowledge about the processes for each module. It should be noted that for surface water (Fig. 2), the sensitivity of the field to runoff and drift plays a major role in comparison with the pesticide property (half-life of a.i. (DT50) variable). This aggregation method enables to cope with cases of compensation between input variables as well as cases of non-compensation (Sadok et al., 2008). For the groundwater surface water and air component of I-PHY, aggregation rules integrate knowledge on the processes. Compensation between variables may occur only when a variable belonging to the 'favourable' class limits pesticide transfer. For instance, this is the case of 'position' variable that indicates that pesticide may be in a position out of reach for leaching or runoff by interception by crop cover or incorporation into soil (see Figs. 1 and 2). For the environment component of I-PHY (Fig. 3), we assumed that low spraying rate compensates a high transfer risk. This is based on some literature data (e.g. Battaglin et al., 2000; De Lafontaine et al., 2014) and pesticide registration data (Tomlin, 2006). Conversely, we do not accept a high level of compensation between the three risk components, groundwater surface water and air. We considered that when one is unfavourable and the rate is high, the situation is unacceptable for stakeholders. This is given by a low score of 2 out 10 for the environment component of I-PHY (Fig. 3), showing a high risk. Finally, in all components of I-PHY, the toxicity or ecotoxicity variable can increase but not decrease the risk. In conclusion, in no case can total compensation occur between input variables.

In order to carry out our study, we constructed some use scenarios for 20 active ingredients for the whole arable area of Reunion. These scenarios were constructed from the known values related to the pesticide properties and the characteristics of the soil (Table 1, variables 1-12) and from values related to the use of the pesticide, considered by the scenarios (Table 1, variables 13-27).

\subsection{Choice of active ingredients studied and their characteristics}

We studied 20 herbicide active ingredients (Table 2). Sixteen active ingredients were herbicides marketed in Reunion between 2009 and 2011, three of which (glyphosate, 2,4-D and S-metolachlor) alone amounted to $80 \%$ of herbicide sales (Maillary, 2012). Three other active ingredients (isoxaflutole, thiencarbazone and nicosulfuron), earmarked to eventually replace some active ingredients, were also studied. Lastly, atrazine 
Table 1

Variables needed for I-PHY calculation, their short name used for this paper.

\begin{tabular}{|c|c|c|c|c|c|}
\hline \multirow[t]{2}{*}{ Nr. } & \multirow[t]{2}{*}{ Variables } & \multicolumn{4}{|l|}{ Values tested } \\
\hline & & Short name & Fixed & Favourable & Unfavourable \\
\hline 1 & Henry's law constant at $25^{\circ} \mathrm{C}\left(\mathrm{Pa} \mathrm{m}^{3} \mathrm{~mol}^{-1}\right)$ & $\mathrm{KH}$ & Pesticide & - & - \\
\hline 2 & Half-life of active ingredient $\left(\right.$ day $\left.^{-1}\right)$ & DT50 & Pesticide & - & - \\
\hline 3 & Acceptable daily intake $\left(\mathrm{mg} \mathrm{kg}^{-1} \mathrm{j}^{-1}\right)$ & ADI & Pesticide & - & - \\
\hline 4 & Aquatox (EC 50, $\mathrm{mg} \mathrm{L}^{-1}$ ) & Aquatox & Pesticide & - & - \\
\hline 5 & Leaching potential index & GUS & Pesticide & - & - \\
\hline 6 & Organic carbon sorption $\left(\mathrm{m} \mathrm{L}^{-1}\right)$ & Кос & Pesticide & - & - \\
\hline 7 & Soil type (sandy, loamy, clayey) & Soil type & Soil & - & - \\
\hline 8 & Soil depth $(<30,30-60,60-90,>90)(\mathrm{cm})$ & Soil depth & Soil & - & - \\
\hline 9 & $\mathrm{pH}(<5,5-5.5,5.5-6,6-6.5,>6.5)$ & $\mathrm{pH}$ & Soil & - & - \\
\hline 10 & Organic carbon content $(<2,2-5,>5)(\%)$ & $\mathrm{OC}$ & Soil & - & - \\
\hline 11 & Absence/existence of swelling clay & Clay & Soil & - & - \\
\hline 12 & Slop $(0,<5,5-10,>10)(\%)$ & Slop & Soil & - & - \\
\hline 13 & Drift-reducing nozzle? & Reducing nozzle & Yes & - & - \\
\hline 14 & Maintenance of nozzle? & Maintenance & Yes & - & - \\
\hline 15 & Is the soil is draining? & Draining & No & - & - \\
\hline 16 & Is the soil filtering? & Filtering & - & No & Yes \\
\hline 17 & Distance between the waterway and the plot & Water-dist & - & $>15 \mathrm{~m}$ & $<5 \mathrm{~m}$ \\
\hline 18 & State of the waterway & Water-state & - & Dry & Full of water \\
\hline 19 & Dry or humid weather & Weather & - & Humid & Dry \\
\hline 20 & Number of days without rainfall (>5 mm) & Rainfall & - & >DT50 a.i. & 0 \\
\hline 21 & Plot cover crop state & Cover-state & - & Total & Without plants \\
\hline 22 & Cover crop occupation (\%) & Cover-occup. & - & 100 & 0 \\
\hline 23 & $\begin{array}{l}\text { Number of } 10 \text {-day periods between the treatment and } \\
\text { the last mower }\end{array}$ & Mower & - & $>4$ & $<1$ \\
\hline 24 & Non-cultivated plant strips downslope (m) & Plant strip & - & $<12 \mathrm{~m}$ & $>6 \mathrm{~m}$ \\
\hline 25 & Application position of the product & Position & - & Into the soil & On bare soil \\
\hline 26 & Type of spray & Spray & - & Hose & $\begin{array}{l}\text { Pressure and airblast } \\
\text { with axial fan spray }\end{array}$ \\
\hline 27 & Type of spray nozzle & Nozzle & - & Other types of nozzle & Classic slit \\
\hline
\end{tabular}



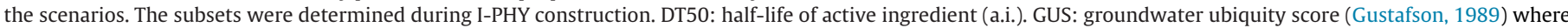

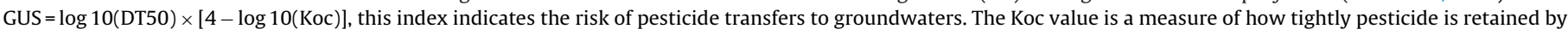
the organic fraction in soils.



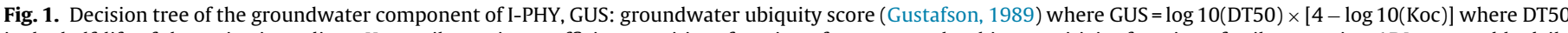


intake of the active ingredient.

was added to our study as a control for past phytosanitary uses.

Pesticide properties related to environmental fate or to the ecotoxicology effect for I-PHY score calculation were (Table 1):

- Henry's law constant $(\mathrm{KH})$ which characterizes the ability of a substance in a solution to volatilize.
- The half-life (DT50) of an active ingredient provides information on the time taken to break down half the quantity of the active ingredient used.

- Acceptable daily intake (ADI) indicates toxicity for humans.

- Aquatox, this variable results from the toxicity of the active ingredient for an invertebrate aquatic organism (Daphnia magna) after $48 \mathrm{~h}$. 


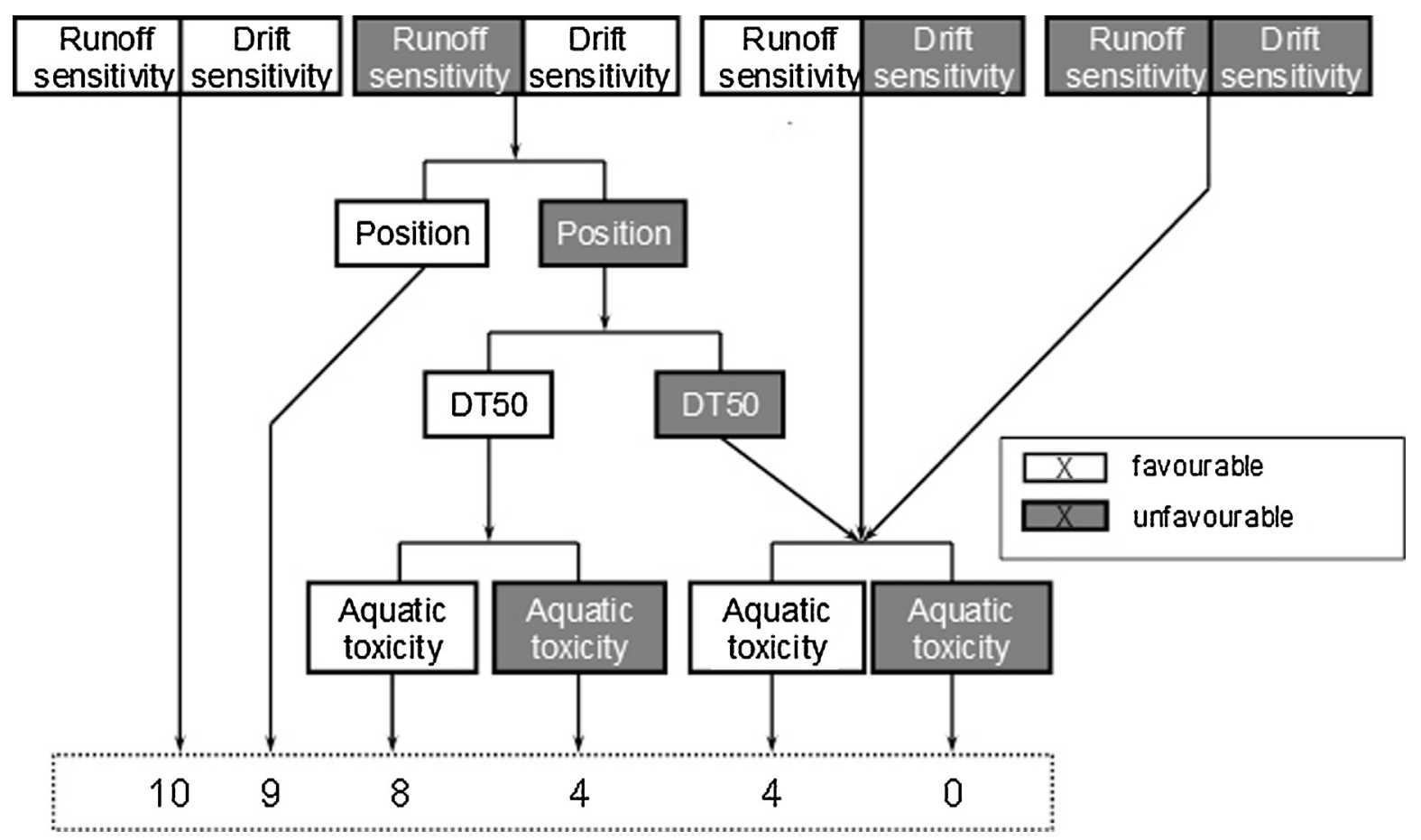

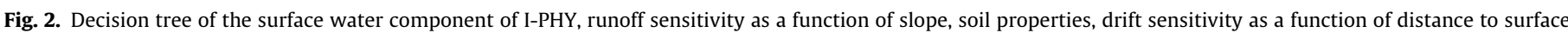
water, position; as a function of crop cover, DT50: half-life of the active ingredient, aquatic toxicity of active ingredient for Daphnia magna.

- Groundwater ubiquity score (GUS). GUS is an index used to estimate the potential of pesticides to contaminate groundwater (Gustafson, 1989). GUS $=\log 10$ (DT50) $\times[4-\log 10$ (Koc)]; the higher the GUS value, the higher the potential for pesticides to move towards groundwater. GUS is a pretty simple indicator but other variables may explain this transfer of pesticides to groundwater (e.g. soil type, $\mathrm{pH}$, matter content...); they are also considered by I-PHY when the GUS value is unfavourable (Fig. 1).
The characteristics of the active ingredients come from the Pesticide Properties Database (University of Hertfordshire, 2013) and are given in Table 2. The active ingredients were studied separately without considering any possible combinations (e.g. such as in commercial specialities) at the approved rate for weeding (active ingredient rate ha ${ }^{-1}$ ) (Ministère de l'agriculture et de l'agroalimentaire, 2013). Finally, we did not study the metabolites of the active ingredients because I-PHY does not allow it.

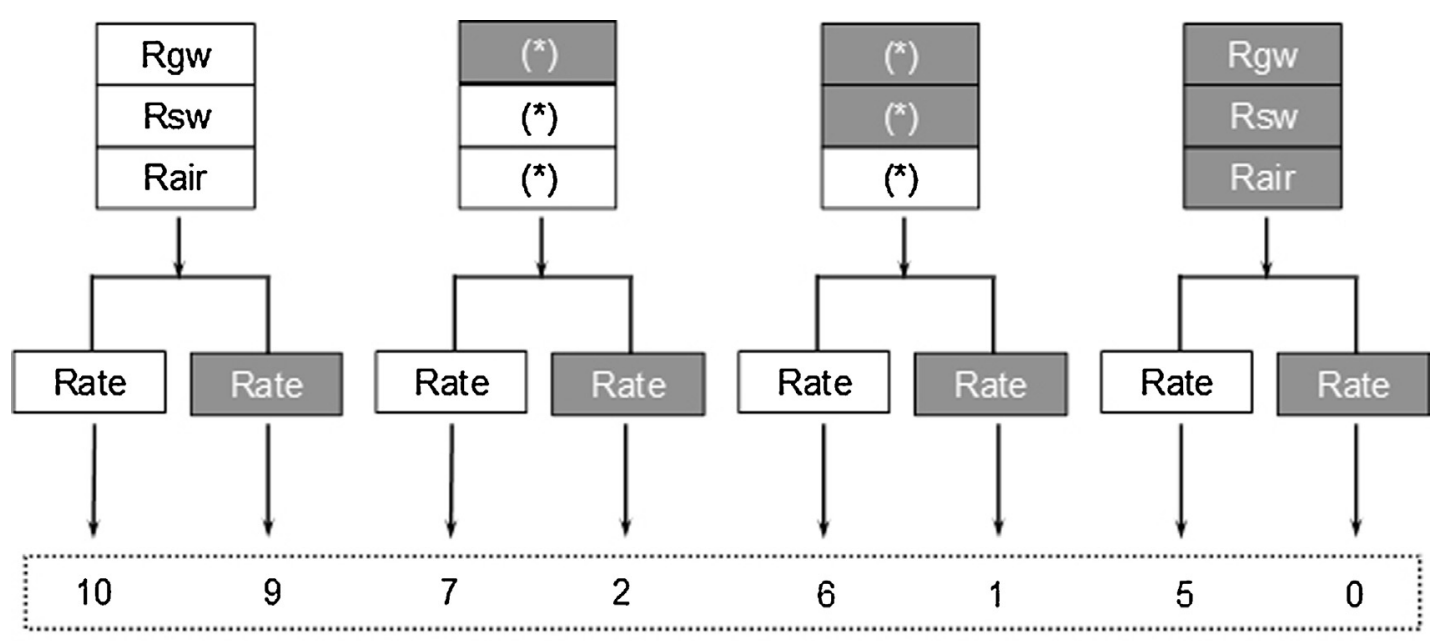

(*) Rgw, Rsw or Rair

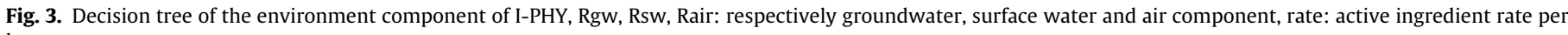
ha. 
Table 2

Characteristics of the 20 active ingredients studied. The characteristics come from the Pesticide Properties Database (University of Hertfordshire, 2013).

\begin{tabular}{|c|c|c|c|c|c|c|c|}
\hline $\begin{array}{l}\text { Active ingredient } \\
\text { Herbicides }\end{array}$ & $\begin{array}{l}\mathrm{KH}\left(25^{\circ} \mathrm{C}\right) \\
\left(\mathrm{Pa} \mathrm{m}^{3} \mathrm{~mol}^{-1}\right)\end{array}$ & DT50 (days) & $\begin{array}{l}\text { ADI (mg kg-1 } \\
\left.\text { day }^{-1}\right)\end{array}$ & $\begin{array}{l}\text { Aquatox } \\
\left(\mathrm{mg} \mathrm{l}^{-1}\right)\end{array}$ & GUS & $\begin{array}{l}\text { Registered rate } \\
\left(\mathrm{g} \mathrm{ha}^{-1}\right)\end{array}$ & $\begin{array}{l}\text { Quantities sold } \\
2009-2011(\mathrm{~kg})\end{array}$ \\
\hline $2,4-D$ & $1.30 \mathrm{E}-05$ & 10 & $5.00 \mathrm{E}-02$ & $1.00 \mathrm{E}+02$ & 1.62 & 960 & 50,531 \\
\hline Aclonifen & $3.03 \mathrm{E}-03$ & 117 & $7.00 \mathrm{E}-02$ & $1.20 \mathrm{E}+00$ & 0.30 & 2700 & 447 \\
\hline Asulam & $1.31 \mathrm{E}-10$ & 3.2 & $3.60 \mathrm{E}-01$ & $5.79 \mathrm{E}+01$ & 1.36 & 3600 & 5539 \\
\hline Atrazine & $1.20 \mathrm{E}-07$ & 75 & $2.00 \mathrm{E}-02$ & $8.50 \mathrm{E}+01$ & 3.30 & 1500 & Removed \\
\hline Bentazone & $7.20 \mathrm{E}-05$ & 13 & $1.00 \mathrm{E}-01$ & $6.40 \mathrm{E}+01$ & 2.30 & 1218 & 92 \\
\hline Diquat & $5.00 \mathrm{E}-12$ & 1000 & $2.00 \mathrm{E}-03$ & $2.20 \mathrm{E}+00$ & -2.68 & 800 & 1900 \\
\hline Fluazifop-P & $4.90 \mathrm{E}-02$ & 1 & $1.00 \mathrm{E}-02$ & $6.20 \mathrm{E}-01$ & 0.00 & 250 & 126 \\
\hline fluroxypyr & $1.69 \mathrm{E}-10$ & 13.5 & $8.00 \mathrm{E}-01$ & $1.00 \mathrm{E}+02$ & 2.42 & 200 & 659 \\
\hline Glufosinate & $8.96 \mathrm{E}-09$ & 7.4 & $2.10 \mathrm{E}-02$ & $6.68 \mathrm{E}+02$ & 1.06 & 750 & 2105 \\
\hline Glyphosate & $4.20 \mathrm{E}-07$ & 12 & $3.00 \mathrm{E}-01$ & $4.00 \mathrm{E}+01$ & 0.91 & 2160 & 52,361 \\
\hline Isoxaflutole & $1.87 \mathrm{E}-05$ & 2 & $2.00 \mathrm{E}-02$ & $1.50 \mathrm{E}+00$ & 0.59 & 99.75 & New \\
\hline Linuron & $2.50 \mathrm{E}-06$ & 48 & $3.00 \mathrm{E}-03$ & $3.10 \mathrm{E}-01$ & 2.03 & 750 & 169 \\
\hline Mesotrione & $5.10 \mathrm{E}-07$ & 32 & $1.00 \mathrm{E}-02$ & $6.22 \mathrm{E}+02$ & 3.43 & 150 & 2141 \\
\hline Metribuzin & $2.00 \mathrm{E}-05$ & 11.5 & $1.30 \mathrm{E}-02$ & $4.90 \mathrm{E}+01$ & 2.57 & 875 & 7678 \\
\hline Nicosulfuron & $1.48 \mathrm{E}-11$ & 26 & $2.00 \mathrm{E}+00$ & $9.00 \mathrm{E}+01$ & 3.79 & 22,5 & New \\
\hline Oxadiazon & $3.80 \mathrm{E}-02$ & 502 & $3.60 \mathrm{E}-03$ & $2.40 \mathrm{E}+00$ & 2.40 & 2400 & 98 \\
\hline Pendimethalin & $2.73 \mathrm{E}-03$ & 90 & $1.25 \mathrm{E}-01$ & $2.80 \mathrm{E}-01$ & -0.39 & 1200 & 4245 \\
\hline S-metolachlor & $2.40 \mathrm{E}-03$ & 45 & $1.00 \mathrm{E}-01$ & $2.35 \mathrm{E}+01$ & 2.72 & 1920 & 21,228 \\
\hline Thiencarbazone & $7.88 \mathrm{E}-13$ & 11.6 & $1.20 \mathrm{E}+00$ & $9.86 \mathrm{E}+00$ & 2.13 & 40 & New \\
\hline Triclopyr & $2.90 \mathrm{E}-03$ & 39 & $3.00 \mathrm{E}-02$ & $1.31 \mathrm{E}+02$ & 3.69 & 3600 & 5131 \\
\hline Favourable subset ${ }^{*}$ & $>2.63 \mathrm{E}-6$ & $<1$ & $>1$ & $>100$ & $<1.8$ & & \\
\hline Unfavourable subset ${ }^{*}$ & $<2.63 \mathrm{E}-4$ & $>30$ & $<0$ & $<0.01$ & $>2.8$ & & \\
\hline Fuzzy logic ${ }^{*}$ & $\begin{array}{l}\text { ]2.63E-6; } \\
2.63 \mathrm{E}-6[\end{array}$ & ]0;30[ & ]0;1[ & ] $0.01 ; 100[$ & ] $1.8 ; 2.8[$ & & \\
\hline
\end{tabular}



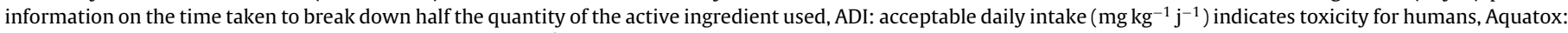



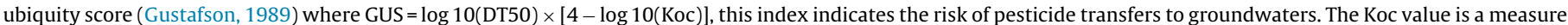
of how tightly pesticide is retained by the organic fraction in soils and the registered rate: the approved dose for weeding ( $\mathrm{g}$ ha ${ }^{-1}$ ) (Maillary, 2012 ).

* Subset value for each variable in I-PHY (Van der Werf and Zimmer, 1998).

\subsection{Variables characterizing the soils of the study site}

Pesticide mobility and fate in a soil are influenced by sorption and degradation processes. The adsorption of a pesticide increases with increased soil organic carbon and clay content, and can slow its movement in soil. Degradation processes depend on the soil type and environmental conditions. In addition, the extent of leaching and runoff is influenced by the soil properties, slope and soil depth. To account for these processes, I-PHY considers 7 variables characterizing soil (Table 1): soil type, soil depth, $\mathrm{pH}$, organic carbon content, absence of swelling clay, slope and filtering nature of the soil. Fig. 4 shows the mapping of all the arable soils on the island of Reunion, carried out with ArcGIS software (ESRI, ArcMap 10.0, 2013). This map was obtained by superposing 6 thematic layers corresponding to the variables characterizing soil, except the filtering nature of the soil; it could not be incorporated into this map through lack of cartographical data. We therefore considered it as a variable of the scenario tested (see Section 2.4. We then divided the total arable area of the island into geographical units of 5 ha each characterized by the combination of the 6 soil variables derived from the centre point of each unit. The map comprises 34,645 geographical units from which 118 distinct soil combinations were identified.

\subsection{Creation of active ingredient use scenarios}

Twenty-seven variables are needed to calculate the I-PHY score (Table 1 ). In order to carry out our study, we created active ingredient use scenarios from the variables needed to take into account the diversity of possible application conditions. There were 15 of these variables (Table 1, variables 16-27) given that the other 12 are linked to pesticide and soil properties (Table 1, variables 1-12). Each variable takes 2 threshold values (unfavourable or favourable) which were used to create the scenarios. In order to limit the number of scenarios, 2 variables related to the characteristics of the equipment used (Nos. 13 and 14, Table 1) were blocked at their favourable threshold values, which amounted to regulatory conditions for good agricultural practices. Likewise, variable no. 15, "draining" was tested with its favourable threshold value as it was a practice not found in Reunion given the major topography of the island enabling such drainage naturally. We therefore constructed our active ingredient use scenarios with the remaining 12 variables, considering their two threshold values. This gave 4096 use scenarios for each pesticide tested $\left(2^{12}\right)$. The scenarios were recorded and processed in a database developed with Access ${ }^{\circledR}$ software (Microsoft Corporation 2010).

\subsection{Statistical analyses}

In the statistical analysis, we sought to prioritize the importance of the values related to the use of the pesticide in the construction of the I-PHY score in order to determine which of them should be acted upon as a priority to increase the score of the indicator. The initial dataset included the 4096 use scenarios applied to each of the 118 soils, for a total of 483,328 I-PHY scores per active ingredient. All the statistical analyses were carried out with R software(Version 2.15.2, R Development Core Team 2013, Vienna, Austria).

Firstly, we sought to reduce the dataset for easier interpretation of the results. We did this using hierarchical cluster classification according to the Ward criterion over the Euclidian distance. The results of this stage enabled us to identify some different soil types leading to the same I-PHY score for the same scenario. We therefore reduced the dataset accordingly, excluding all the doublets.

Secondly, the I-PHY score variation (called gain) was calculated for each soil type, each active ingredient, and each variable. The gain was calculated from the difference between 2 equal scenarios, except the value of the variable analyzed. If a variable had no gain, the variable and the 2 scenarios were deleted from the dataset. Then, based on this reduced dataset, we used CART (Breiman et al., 1984), a statistical method that successively divides up observations, by binary divisions, into subsets (called nodes), which are 


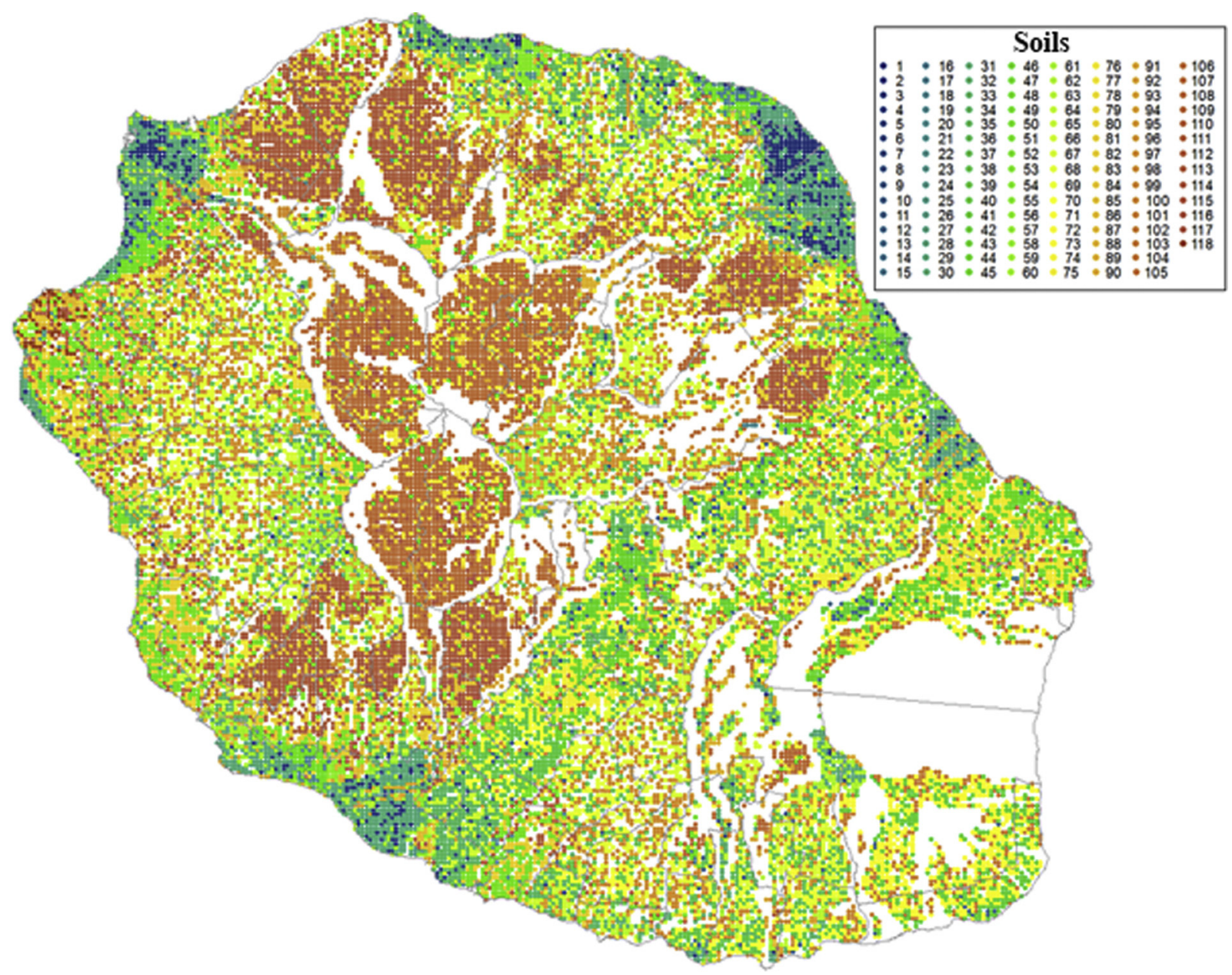

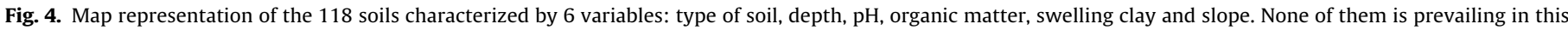
territory. The white zones are non-arable areas (volcano, river bed, etc.) created with ArcMAP software (ESRI, 2013).

increasingly uniform in relation to a target variable; in this case the I-PHYscore. The results were displayed in the form of a regression tree (Fig. 5). The quality of the divisions was measured by the decrease in the mean squared error induced by the division. The selected variable was the one that induced the largest decrease in mean squared error. The procedure was repeated until subsets were obtained that had very few observations. If the condition of this selected variable was true (unfavourable subset of variable, Table 1), the initial observations were sent to the left of the parent node. If the condition of this selected variable was false (favourable subset of variable, Table 1 ), the observations were sent to the right of the parent node. Finally, the I-PHY min score corresponded to the scenario where all the variables were in their unfavourable conditions, i.e. the poorest application conditions for the active ingredient. The I-PHY minimum score is given at the bottom left of the regression tree (Fig. 5). Conversely, the I-PHY maximum score corresponded to the scenario where all the variables were in their favourable conditions, i.e. the best application conditions for the active ingredient. The I-PHY max score is given at the bottom right of the regression tree (Fig. 5).

Lastly, we compared the importance of the variables in the construction of the I-PHY score between active ingredients and all soils combined. We did this using the random forests statistical method (Breiman, 2001). This method is based on the aggregation of several trees disrupted by double randomization, of both the sample (bootstrap sample, i.e. with the drawing and returning of $n$ observations out of the initial $n$ observations), but also some explanatory variables (sub-sets of explanatory variables selected from all the initial variables). A regression tree was constructed from all these samples (500 in our case), with a random draw of the sub-sets of explanatory variables (of the $p$ initial variables, $p / 3$ were drawn randomly) to search for each optimum division. The importance of the variables in the construction of the I-PHY was then defined by the mean decrease in heterogeneity. As this measurement was not calculated on the same sample for the active ingredients, we rounded it off to an index between 0 and 100. These index values then enabled us to construct uniform groups of active ingredients according to the importance of the variables for the I-PHY score using a principal components analysis (PCA) followed by hierarchical ascendant clustering. Lastly, the differences in the mean, minimum and maximum I-PHY scores for the different groups were tested using Kruskal-Wallis and Wilcoxon comparison of multiple means tests.

\section{Results and discussion}

\subsection{The validity of I-PHY scores}

The mean, minimum (min) and maximum ( $\max$ ) I-PHY scores for the 4096 scenarios tested on the 118 soils for each active ingredient are presented in Table 3. The mean scores varied from 3.72 (triclopyr) to 8.72 (thiencarbazone). The I-PHY min scores of the different active ingredients varied from 2.36 (triclopyr) to 6.04 
Table 3

The minimum, maximum, room for progress between minimum and maximum, mean ( \pm standard deviation) of the I-PHY scores for 20 active ingredients.

\begin{tabular}{|c|c|c|c|c|}
\hline Active ingredient & I-PHY minimum & I-PHY maximum & Room for progress (max-min) & I-PHY mean \\
\hline $2,4-\mathrm{D}$ & 4.78 & 8.37 & 3.59 & $7.25( \pm 0.88)$ \\
\hline Aclonifen & 3.51 & 6.02 & 2.51 & $4.97( \pm 0.73)$ \\
\hline Asulam & 4.60 & 9.03 & 4.43 & $8.30( \pm 0.85)$ \\
\hline Atrazine & 3.63 & 8.93 & 5.30 & $6.04( \pm 1.52)$ \\
\hline Bentazon & 3.98 & 7.90 & 3.92 & $6.28( \pm 0.87)$ \\
\hline Diquat & 4.48 & 9.21 & 4.73 & $7.59( \pm 1.24)$ \\
\hline Fluazifop-P & 4.63 & 7.54 & 2.91 & $6.41( \pm 0.84)$ \\
\hline Fluroxypyr & 5.00 & 9.50 & 4.50 & $6.90( \pm 0.63)$ \\
\hline Glufosinate & 4.92 & 9.21 & 4.3 & $8.29( \pm 0.90)$ \\
\hline Glyphosate & 4.86 & 9.07 & 4.21 & $8.28( \pm 0.85)$ \\
\hline Isoxaflutole & 5.02 & 8.94 & 3.92 & $7.90( \pm 0.87)$ \\
\hline Linuron & 4.37 & 9.21 & 4.84 & $7.55( \pm 1.16)$ \\
\hline Mesotrione & 3.85 & 9.26 & 5.41 & $6.57( \pm 1.51)$ \\
\hline Metribuzin & 3.87 & 8.11 & 4.24 & $6.10( \pm 1.05)$ \\
\hline Nicosulfuron & 4.90 & 9.51 & 4.61 & $7.52( \pm 1.22)$ \\
\hline Oxadiazon & 2.81 & 4.48 & 1.67 & $3.80( \pm 0.39)$ \\
\hline Pendimethalin & 4.24 & 6.67 & 2.43 & $5.78( \pm 0.67)$ \\
\hline S-metolachlor & 3.16 & 6.19 & 3.03 & $4.59( \pm 0.75)$ \\
\hline Thiencarbazone & 5.73 & 9.60 & 3.87 & $8.72( \pm 0.78)$ \\
\hline Triclopyr & 2.36 & 5.28 & 2.92 & $3.72( \pm 0.72)$ \\
\hline
\end{tabular}

(fluoxypyr). The I-PHY max scores varied from 4.48 (oxadiazon) to 9.60 (thiencarbazone). These results made it possible at this stage to identify some active ingredients for which the score was under the acceptable level of the I-PHY indicator (score < 7). Ten out of 20 pesticides were in this case.

The question of the validity of the score still remained. In that respect, Bockstaller and Girardin (2003) and Bockstaller et al. (2008) proposed comparing the results of the indicator with measurements of pesticide concentrations in water. Such a comparison means accepting a change in study scale but also accepting its limitations. Indeed, water contamination, especially surface water, is always found after a major climate event (Louchart et al., 2001) while sampling to monitor water quality is usually carried out without considering these risk periods (Voltz et al., 2005). When comparing these I-PHY scores with water quality measurements in Reunion (Badat, 2011), we found that 7 active ingredients (and their associated metabolites) studied in this article accounted for $72 \%$ of total detections (in surface waters and groundwaters): atrazine (56\%), metolachlor (8\%), bentazon (2\%), triclopyr (2\%), glyphosate (2\%), 2,4-D (1.5\%) and metribuzine (0.5\%). Apart from 2,4-D and glyphosate, the other active ingredients had the lowest mean and minimum I-PHY values. In addition, the same herbicides are regularly incriminated in water pollution in many tropical or temperate countries (Daniel et al., 2002; Haarstad and Ludvigsen, 2007; Ghosh and Singh, 2013). Indeed, 2,4-D and glyphosate alone account for over $2 / 3$ of pesticide sales in Reunion (Maillary, 2012). It is likely that detection of those herbicides in the waters in Reunion is also the consequence of strong pressure linked to the volumes applied and/or to inappropriate cultural practices. I-PHY cannot consider that risk on a territory scale because, by its very construction, it assesses risks on small quantities of pesticides applied on a field scale. However, the I-PHY min values for these two active ingredients were 4.78 for 2,4-D and 4.86 for glyphosate (Table 3); these results indicate a high risk of transfer to the environment under the poorest application conditions. This brief comparison of the results of our study with measured contamination enables us to suggest that the I-PHY indicator seems relevant for identifying most substances presenting environmental risks.

\subsection{Regression trees as decision-support tools}

The hierarchical cluster classification enabled us to identify some different soil types leading to the same I-PHY score for the same scenario. This classification led to 9 different soil types for
11 active ingredients (2,4-D, aclonifen, asulam, diquat, fluazifop-P, glufosinate, glyphosate, isoxaflutole, linuron, pendimethalin and thiencarbazone), 37 soil types for triclopyr and 45 soil types for the last 8 active ingredients studied (atrazine, bentazon, fluroxypyr, mesotrione, metribuzine, nicosulfuron, oxadiazon and S-metolachlor). Then, 496 regression trees were constructed (1 regression tree for each type of soil and per active ingredient) using the CART method. None of the regression trees constructed was identical. The number of nodes making up these trees notably determined their complexity. Fig. 5 shows the 2,4-D regression tree for the most common soil in Reunion; 9 other regression trees for 9 active ingredients are given in the supplementary data (Figs. 7-15). These regression trees enabled us to visualize the importance of the variables in the construction of the I-PHY score. The score at the top of the tree corresponds to the mean of the scenarios, which is reduced or increased depending on the unfavourable or favourable threshold values of the variables involved in the construction of the tree. The leaves of the trees (red, orange or green squares) indicate the final I-PHY scores, with the minimum score furthest left and the maximum score furthest right for the active ingredient on the soil type considered. The difference between these two scores was used to estimate the possible room for improvement. These trees also made it possible to visualize the variables according to the gains they could provide. The more the variable is located near the top of the tree the greater was the gain it provided in the construction of the I-PHY score. From one soil to another, or from one active ingredient to another, the prioritization of these variables and their interactions differed (see supplementary data, Figs. 7-15).

The CART method (Breiman et al., 1984) is one of the few nonparametric methods that offer a way of computing the importance of variables (Bel et al., 2009). This method builds classification and regression trees for predicting continuous dependent variables (regression) and categorical predictor variables (classification). CART procedures have proven to be very useful in ecological and environmental contexts because the outputs are easily understood (De'ath and Fabricius, 2000). CART models have several additional advantages over other techniques: input data do not need to be normally distributed; it is not necessary for predictor variables to be independent; and non-linear relationships between predictor variables and observed data can be modelled (Bel et al., 2009). Thus, classification and regression trees by CART represent an alternative to many traditional statistical techniques, including multiple regression, analysis of variance, logistic regression, log-linear 




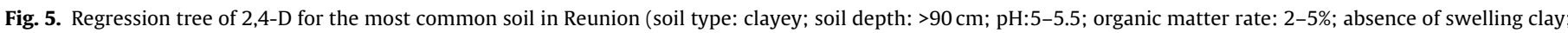



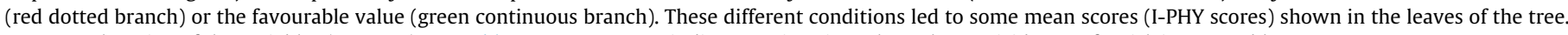
For an explanation of the variables (spray...), see Table 2. A score over 7 indicates a situation where the pesticide transfer risk is acceptable.

models and linear discriminant analysis (De'ath and Fabricius, 2000). Under these conditions, regression trees can be used for interactive exploration and for the description and prediction of patterns and processes. In our case, regression trees enabled us to identify and prioritize importance variables for the I-PHY indicator, for each herbicide under our study conditions. The tree is represented graphically, and this aids exploration and understanding. Such an analysis proves decisive for using this type of indicator (Hak et al., 2012) as it makes it possible to determine the exact weight of each of the variables making up the indicator (Ferrara et al., 2012).

\subsection{Room for manoeuvre to reduce herbicide environmental impacts}

The random forests statistical method was used to determine the importance of the variables in the I-PHY score construction. Even though all the variables contributed to this construction except the 'cover-occup' variable (Table 4), only four variables were very significant. These were the 'spray', 'water-dist', 'water-state' and 'position' variables. However, the importance of these variables varied with the pesticide. This first analysis completed by a principal components analysis brought out 3 groups of active ingredients according to their variables of importance in the construction of the I-PHY scores. These groups were represented in the first factorial plane of the analysis (Fig. 6). Axes 1 and 2 explained over $83 \%$ of this graphic representation. Each of the 3 groups included one of the 3 active ingredients most used in Reunion, so we therefore called these groups by the ingredient names: '2,4-D' group, 'glyphosate' group and 'S-metolachlor' group. For the ingredients in the '2,4D' group, the 'spray' variable was the main variable of importance in the I-PHY score then, to a lesser degree, the 'water-dist' and 'water-state' variables. Conversely, for the ingredients in the 'glyphosate' group, the 2 variables of importance were 'water-dist' and 'water-state' then the 'spray' variable. For the active ingredients in the 'S-metolachlor' group, the variable of importance was

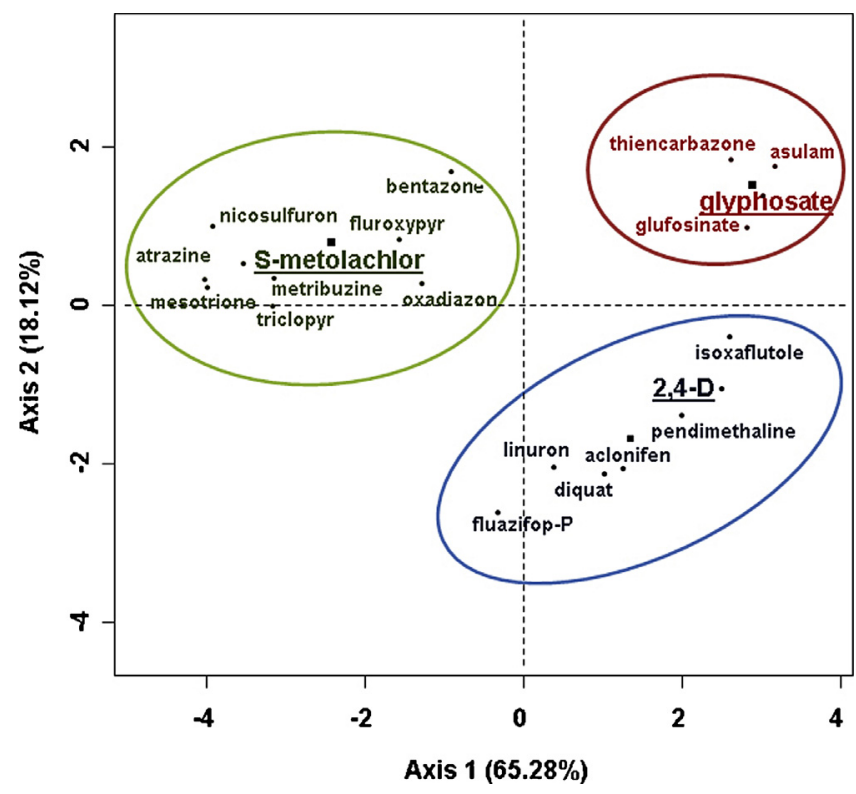

Fig. 6. Individual factor map of the PCA of importance measurements for the variables of all the active ingredients. The two axes represent $83 \%$. Three groups can be distinguished, each represented by one of the most widely used active ingredients on the island of Reunion: group 1: 2,4-D, group 2: glyphosate and group 3: S-metolachlor. 
Table 4

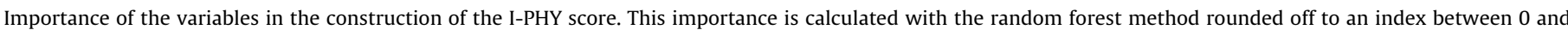

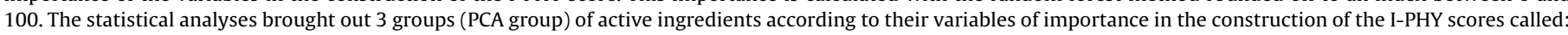
'2,4-D’ group, 'glyphosate' group and 'S-metolachlor' group (S-meto in the table). Variables needed for I-PHY calculation: see Table 1.

\begin{tabular}{|c|c|c|c|c|c|c|c|c|c|c|c|c|c|}
\hline Active Ingredient & Spray & Water-dist & Water-state & Posi. & Cover-state & Rain. & Mower & Filte. & Plant strip & Nozzle & Weather & Cover-occup & PCA group \\
\hline $2,4-D$ & 37.2 & 27.1 & 27.7 & 1.3 & 2.7 & 3.0 & 0.2 & 0.0 & 0.4 & 0.3 & 0.0 & 0.0 & $2,4-\mathrm{D}$ \\
\hline Aclonifen & 52.2 & 20.7 & 19.7 & 2.1 & 4.2 & 0.0 & 0.2 & 0.0 & 0.6 & 0.3 & 0.0 & 0.0 & $2,4-\mathrm{D}$ \\
\hline Asulam & 6.8 & 39.8 & 41.0 & 1.8 & 4.5 & 5.0 & 0.2 & 0.0 & 0.7 & 0.2 & 0.0 & 0.0 & glyphosate \\
\hline Atrazine & 12.2 & 6.2 & 6.3 & 68.1 & 0.5 & 0.2 & 4.5 & 1.9 & 0.1 & 0.0 & 0.1 & 0.0 & S-meto \\
\hline Bentazon & 21.8 & 20.1 & 20.1 & 29.2 & 2.4 & 2.5 & 2.6 & 0.9 & 0.2 & 0.2 & 0.0 & 0.0 & S-meto \\
\hline Diquat & 56.0 & 17.8 & 17.7 & 2.5 & 4.8 & 0.0 & 0.2 & 0.0 & 0.7 & 0.3 & 0.0 & 0.0 & $2,4-\mathrm{D}$ \\
\hline Fluazifop-P & 67.7 & 14.2 & 14.1 & 0.8 & 1.3 & 1.3 & 0.1 & 0.0 & 0.2 & 0.3 & 0.0 & 0.0 & $2,4-\mathrm{D}$ \\
\hline Fluroxypyr & 19.5 & 18.7 & 19.1 & 33.9 & 2.4 & 2.5 & 2.6 & 0.9 & 0.2 & 0.2 & 0.0 & 0.0 & S-meto \\
\hline Glufosinate & 18.1 & 36.5 & 35.2 & 1.8 & 3.6 & 4.0 & 0.2 & 0.0 & 0.5 & 0.2 & 0.0 & 0.0 & glyphosate \\
\hline Glyphosate & 10.3 & 39.1 & 39.6 & 1.6 & 3.9 & 4.4 & 0.2 & 0.0 & 0.6 & 0.2 & 0.0 & 0.0 & glyphosate \\
\hline Isoxaflutole & 35.0 & 28.5 & 27.6 & 1.6 & 3.1 & 3.4 & 0.2 & 0.0 & 0.4 & 0.2 & 0.0 & 0.0 & $2,4-\mathrm{D}$ \\
\hline Linuron & 54.9 & 18.6 & 18.6 & 2.7 & 2.2 & 2.0 & 0.5 & 0.0 & 0.3 & 0.3 & 0.0 & 0.0 & $2,4-D$ \\
\hline Mesotrione & 12.0 & 5.1 & 5.1 & 71.5 & 0.3 & 0.3 & 3.4 & 2.1 & 0.0 & 0.0 & 0.1 & 0.0 & S-meto \\
\hline Metribuzin & 13.7 & 11.3 & 11.3 & 57.1 & 1.0 & 1.1 & 3.2 & 1.0 & 0.1 & 0.1 & 0.1 & 0.0 & S-meto \\
\hline Nicosulfuron & 15.8 & 12.1 & 11.8 & 53.4 & 0.9 & 1.0 & 2.0 & 2.8 & 0.1 & 0.1 & 0.1 & 0.0 & S-meto \\
\hline Oxadiazon & 15.6 & 13.8 & 14.1 & 50.5 & 4.3 & 0.0 & 0.4 & 0.6 & 0.6 & 0.1 & 0.0 & 0.0 & S-meto \\
\hline Pendimethalin & 40.3 & 26.5 & 26.3 & 1.5 & 3.0 & 1.4 & 0.2 & 0.0 & 0.5 & 0.3 & 0.0 & 0.0 & 2,4-D \\
\hline S-metolachlor & 13.8 & 11.2 & 11.0 & 55.5 & 1.0 & 0.3 & 5.4 & 1.5 & 0.1 & 0.1 & 0.0 & 0.0 & S-meto \\
\hline Thiencarbazone & 14.0 & 33.7 & 33.4 & 9.2 & 3.8 & 4.0 & 1.3 & 0.1 & 0.5 & 0.1 & 0.0 & 0.0 & glyphosate \\
\hline Triclopyr & 15.3 & 9.9 & 10.0 & 56.2 & 0.5 & 0.5 & 6.7 & 0.7 & 0.1 & 0.1 & 0.0 & 0.0 & S-meto \\
\hline
\end{tabular}

the 'position' variable then, to a lesser degree, the 'water-dist', 'water-state' and 'spray' variables. When considering the I-PHY scores, the mean and minimum scores for the active ingredients in the 'glyphosate' group were significantly greater than those of the 'S-metolachlor' group. The mean scores were 5.57 for the ' $\mathrm{S}$ metolachlor' group as opposed to 8.54 for the 'glyphosate' group with a $p$-value of 0.00062 . The minimum scores were 3.57 for the 'S-metolachlor' group as opposed to 5.38 for the 'glyphosate' group with a $p$-value of 0.0018 . However, the I-PHY mean and minimum scores for the 'S-metolachlor' group did not differ from those of the '2,4-D' group. Lastly, the maximum I-PHY scores for the 3 groups were not statistically different: 7.96 for the '2,4-D' group, 9.32 for the 'glyphosate' group and 7.45 for the 'S-metolachlor' group. This last point shows that the conditions under which these active ingredients were used had a strong impact on the scores.

With a view to limiting the environmental impacts of herbicides, our results showed that replacing the active ingredients of the ' $\mathrm{S}$ metolachlor' group with those of the 'glyphosate' group would be worthwhile. Unfortunately, this is not always possible because the active ingredients do not always have the same target (monocotyledonous or dicotyledonous weeds) and the same modes of action (pre or post-emergence). If the substitution of active substances is not possible, regression trees can help farmers to identify variables of importance constituting their own room for manoeuvre. We found that farmers had possibilities to act upon these different variables of importance. Those possibilities were either partial for the 'water-dist' and 'water-state' variables, or total for all the others. Our results showed that four variables mainly affected the I-PHY score and this importance varied depending on the pesticide group. However, the comparison of these results with literature, suggests that I-PHY probably minimizes the specific risks linked to major rainfall events given the main variables we identified that influence its score. In fact, while the two variables linked to the proximity of a water point ('dist-state' and 'water-state') logically influenced the I-PHY scores whatever the active ingredient (Haarstad and Ludvigsen, 2007), the 'rainfall' variable only had a moderate impact on this score. Yet, that variable was considered very important in some other case studies (Louchart et al., 2001; Hermosin et al., 2013) and particularly in a tropical climate (Damm and Van den Brink, 2010). Bernard et al. (2005) showed that whatever the type of soil considered, the risks of groundwater pollution during heavy rainfall ( $>50 \mathrm{~mm} \mathrm{day}^{-1}$ ) by all the active ingredients they studied were proven. Included in these ingredients and those we assessed figured atrazine, triclopyr and 2,4-D. Davis et al. (2011) also showed that the risks of surface water pollution linked to herbicides (atrazine) on a crop such as sugarcane mainly arose from irrigation practices just after herbicide application. This practice is widely used in Reunion, particularly to increase the effectiveness of pre-emergence herbicides such as S-metolachlor. I-PHY does not consider irrigation practices and they could be included with the 'rainfall' variable, which would all the more warrant increasing the weight of that variable.

\section{Conclusion}

Our methodology enabled us to identify and prioritize importance variables for the I-PHY indicator, for each herbicide under our study conditions. Such an analysis proves decisive for using this type of indicator as it makes it possible to limit the "black box" image of these indicators. As such, these variables become levers for action upon which users of these herbicides can act to limit the risk of transfers to the environment. We tested some scenarios based on the extreme threshold values of the variables (favourable and unfavourable) in order to determine the maximum room for improvement. In practice, and for an ex ante risk assessment, some variables can be blocked at their true values relative to the actual conditions of use. This makes it possible to reduce the number of scenarios and, thereby, the complexity of the regression trees. These trees then become decision-support tools specific to each user and provide customized advice enabling users to take appropriate decisions with a view to achieving their objectives. In order to help farmers, this decision-support tool is now available as an application, called Phyto'Aide, on our web applications platform (www.margouilla.net/phyto_aide). This tool, based on an open source code, is completely free and the user friendly interface allows the farmer, or any user, to select an active ingredient and soil parameters to acquire a regression tree and then advice. It provides users with a tutorial to understand the method, how to interpret the tree and to know which actions can be taken.

\section{Acknowledgments}

We should like to express our warm thanks to all stakeholders of the agricultural sector and the French administration for their 
extensive involvement in this work. We thank Peter Biggins from CIRAD for his linguistic support. We thank the anonymous reviewers who helped improve the quality of the manuscript. The project was co-financed by the European Union and the Reunion Island Region.

\section{Appendix A. Supplementary data}

Supplementary data associated with this article can be found, in the online version, at http://dx.doi.org/10.1016/j.ecolind. 2015.02.020.

\section{References}

Badat, 2011. Etat de la ressource et des usages de l'eau à la Réunion - 2010. In: Office de l'eau Réunion, Saint-Denis, France.

Battaglin, W.A., Furlong, E.T., Burkhardt, M.R., Peter, C.J., 2000. Occurrence of sulfonylurea, sulfonamide, imidazolinone, and other herbicides in river, reservoirs and ground water in the Midwestern United States, 1998. Sci. Total Environ. 248, 123-133.

Bel, L., Allard, D., Laurent, J.M., Cheddadi, R., Bar-Hend, A., 2009. CART algorithm for spatial data: application to environmental and ecological data. Comput. Stat. Data Anal. 53, 3082-3093.

Bernard, H., Chabalier, P.F., Chopart, J.L., Legube, B., Vauclin, M., 2005. Assessment of herbicides leaching risk in two tropical soils of Reunion Island. J. Environ. Qual. 34, 534-546.

Bockstaller, C., Girardin, P., 2003. How to validate environmental indicators. Agric. Syst. 76, 639-653.

Bockstaller, C., Wohlfahrt, J., Hubert, A., Hennebert, P., Zahm, F., Vernier, F., Mazzela, N., Keichinger, O., Girardin, P., 2008. Les indicateurs de risque de transfert de produits phytosanitaires et leur validation: exemple de l'indicateur I-Phy. Ingénieries 86, 103-114.

Bockstaller, C., Guichard, L., Keichinger, O., Girardin, P., Galan, M.B., Gaillard, G., 2009. Comparison of methods to assess the sustainability of agricultural systems, a review. Agron. Sustain. Dev. 29, 223-235.

Breiman, L., 2001. Random Forests. Statistics Department, University of California, Berkeley, USA.

Breiman, L., Friedman, J.H., Olshen, R.A., Stone, C.J., 1984. Classification and Regression Trees. Chapman/Hall Wadsworth, USA.

Damm, M.A., Van den Brink, P.J., 2010. Implications of differences between temperate and tropical freshwater ecosystems for the ecological risk assessment of pesticides. Ecotoxicology 19, 24-37.

Daniel, P.E., Bedmar, F., Costa, J.L., Aparicio, V.C., 2002. Atrazine and metribuzin sorption in soils of the Argentinean humid pampas. Environ. Toxicol. Chem. 21, 2567-2572

Davis, A.M., Thorburn, P.J., Lewis, S.E., Bainbridge, Z.T., Attard, S.J., Milla, R., Brodie, J.E., 2011. Environmental impacts of irrigated sugarcane production: herbicide run-off dynamics from farms and associated drainage systems. Agric. Ecosyst. Environ. 180, 123-135.

De Lafontaine, Y., Beauvais, C., Cessna, A.J., Gagnon, P., Hudon, C., Poissant, L., 2014. Sulfonylurea herbicides in an agricultural catchment basin and its adjacent wetland in the St. Lawrence River basin. Sci. Total Environ. 479, $1-10$.

Devillers, J., Farret, R., Girardin, P., Rivière, J.-L., Soulas, G., 2005. Indicateurs pour évaluer les risques liés à l'utilisation des pesticides. Tec \& Doc, Lavoisier, Paris.

De'ath, G., Fabricius, K.E., 2000. Classification and regression trees: a powerful yet simple technique for ecological data analysis. Ecology 81, 3178-3198.

FAOSTAT. Pesticides (use). http://data.fao.org/dataset?entryld=5e70fee4-fb6543b6-8da1-b6de4626b9bd\&tab=metadata (accessed 18.02.13).
Ferrara, A., Salvati, L., Sateriano, A., Nolè, A., 2012. Performance evaluation and cost assessment of a key indicator system to monitor desertification vulnerability. Ecol. Indic. 23, 123-129.

Ghosh, R.K., Singh, N., 2013. Adsorption-desorption of metolachlor and atrazine in Indian soils: effect of fly ash amendment. Environ. Monit. Assess. 185, 1833-1845.

Gustafson, D.I., 1989. Groundwater ubiquity score: a simple method for assessing pesticide leachability. Environ. Toxicol. Chem. 8, 339-357.

Haarstad, K., Ludvigsen, G.H., 2007. Ten years of pesticide monitoring in Norwegian ground water. Ground Water Monit. R 27, 75-89.

Hak, T., Kovanda, J., Weinzettel, J., 2012. A method to assess the relevance of sustainability indicators: application to the indicator set of the Czech Republic's Sustainable Development Strategy. Ecol. Indic. 17, 46-57.

Hermosin, M.C., Calderon, M.J., Real, M., Cornejo, J., 2013. Impact of herbicides used in olive groves on waters of the Guadalquivir river basin (southern Spain). Agric. Ecosyst. Environ. 164, 229-243.

Lin, Y.J., Makesh, K., Anugrah, S., Gian, G., 1999. Effect of simulated sunlight on atrazine and metolachlor toxicity of surface waters. Ecotoxicol. Environ. Saf. 43, 35-37.

Louchart, X., Voltz, M., Andrieux, P., Moussa, R., 2001. Herbicides runoff at field and watershed scales in a Mediterranean vineyard area. J. Environ. Oual. 30, 982-991.

Maillary, 2012., 2012. Base nationale des ventes des distributeurs 2009-2010 et 2011. DAAF, Saint-Pierre, France.

Ministère de l'agriculture et de l'agroalimentaire, 2013. e-phy, le catalogue des produits phytopharmaceutiques et de leurs usages des matières fertilisantes et des supports de culture homologués en France, http://e-phy.agriculture.gouv.fr| (accessed 07.06.12)

Mottes, C., Lesueur-Jannoyer, M., Le Bail, M., Malézieux, E., 2013. Pesticide transfer models in crop and watershed systems: a review. Agron. Sustain. Dev. http://dx.doi.org/10.10007/s13593-013-0176-3 (online first).

Oliver, D.P., Kookana, R.S., 2006. On-farm management practices to minimize off-site movement of pesticides from furrow irrigation. Pest Manag. Sci. 62, 899-911.

Payraudeau, S., Gregoire, C., 2012. Modelling pesticides transfer to surface water at the catchment scale: a multi-criteria analysis. Agron. Sustain. Dev. 32, 479-500.

Pedlowski, M.A., Canela, M.C., Da Costa Terra, M.A., Ramos de Faria, R.M., 2012. Modes of pesticides utilization by Brazilian smallholders and their implications for human health and the environment. Crop Prot. 31, 113-118.

Reichenberger, S., Bach, M., Skitschak, A., Frede, H.G., 2007. Mitigation strategies to reduce pesticide inputs into ground and surface water and their effectiveness, a review. Sci. Total Environ. 384, 1-35.

Reus, J., Leendertse, P., Bockstaller, C., Fomsgaard, I., Gutsche, V., Lewis, K., et al., 2002. Comparison and evaluation of eight pesticide environmental risk indicators developed in Europe and recommendations for future use. Agric. Ecosyst. Environ. 90, 177-187.

Sadok, W., Angevin, F., Bergez, J.-E., Bockstaller, C., Colomb, B., Guichard, L., Reau, R. Doré, T., 2008. Ex ante assessment of the sustainability of alternative cropping systems: guidelines for identifying relevant multi-criteria decision aid methods. Agron. Sustain. Dev. 28, 163-174.

Tomlin, C.D.S. (Ed.), 2006. The Pesticide Manual. , 14th ed. British Crop Protection Council, Farnham, United Kingdom, p. 1349.

University of Hertfordshire, 2013. The Pesticide Properties DataBase (PPDB) Developed by the Agriculture \& Environment Research Unit (AERU). University of Hertfordshire, 2006-2013. http://sitem.herts.ac.uk/aeru/ppdb/en/atoz.htm (accessed 07.06.12).

Van der Werf, H.M.G., Zimmer, C., 1998. An indicator of pesticide environmenta impact based on a fuzzy expert system. Chemosphere 36, 2225-2249.

Voltz, M., Alix, A., Barriuso, E., Bedos, C., Bonicelli, B., Caquet, T., Dubus, I., Gascuel, C., Gril, J.N., 2005. Devenir et transfert des pesticides dans l'environnement et impacts biologiques. In: Aubertot, J.N., Barbier, J.M., Carpentier, A., Gril, J.N., Guichard, L., Lucas, P., Savary, S., Voltz, M. (Eds.), Pesticides, agriculture et environnement - Réduire l'utilisation des pesticides et en limiter les impacts environnementaux, Expertise scientifique collective INRA-Cemagref, chapitre vol. 3, pp. 1-219. 